\title{
Comparison of Glenohumeral Range of Motion Deficits in Youth, Collegiate, and Professional Baseball Players
}

\author{
C. Luke Wilcox, DO ${ }^{1}$, Hillary A. Plummer, PhD, ATC ${ }^{2}$ (1) ${ }^{\text {, }}$, Roger V. Ostrander III, MD ${ }^{3}$
}

${ }^{1}$ Department of Sports Medicine, Michigan State University, ${ }^{2}$ Andrews Research \& Education Foundation, ${ }^{3}$ Andrews Institute for Orthopaedics \& Sports Medicine

Keywords: pitching, throwing, sports medicine, sports, shoulder, injury, glenohumeral joint

https://doi.org/10.26603/001c.29683

\section{International Journal of Sports Physical Therapy}

Vol. 16, Issue 6, 2021

\section{Background}

Examining range of motion deficits across levels of baseball competition can result in a better understanding of the extent of altered range of motion patterns and identify competition levels that may require preventative interventions that target the deficits.

\section{Purpose}

The purpose of this study was to compare shoulder range of motion in baseball players across levels of competition and compare the prevalence of glenohumeral internal rotaton deficit (GIRD) and total arc of motion differences (TAMD) between competition levels in pitchers and position players.

\section{Study Design}

Prospective descriptive cohort

\section{Methods}

Passive internal and external rotation range of motion was measured bilaterally. Individuals with current pain in the arm, shoulder, elbow or shoulder surgery within the prior two years were excluded. Measurements were taken during pre-season physical examinations. Players were divided into seven groups: $12 \mathrm{u}$ (11-12 years; $n=30), 14 u$ (13-14 years; $n=30$ ), High School 1 (HS 1; 15-16 year; $n=42$ ), High School 2 (HS 2; 17-18 years; $n=25$ ), College ( $n=22$ ), Professional 1 (Pro1; 17-22 years; $n=37$ ) and Professional 2 (Pro2; 23 and older; $n=37$ ). Multiple one-way analyses of variance were performed to determine differences between groups. Tukey test for post-hoc analysis was employed to determine which competition levels were significantly different.

\section{Results}

Two-hundred and twenty-three male baseball players ages 11-26 participated. The $12 \mathrm{u}$ $\left(53.7^{\circ}\right)$ and $14 \mathrm{u}\left(54.2^{\circ}\right)$ groups had significantly less internal rotation than HS1 $\left(65.2^{\circ}\right)$, HS2 $\left(63.9^{\circ}\right)$, College $\left(62.3^{\circ}\right)$, Pro1 $\left(64.9^{\circ}\right)$, and Pro2 $\left(64.5^{\circ}\right)$ players $(\mathrm{p}<0.0001)$. The $12 \mathrm{u}$, $14 \mathrm{u}, \mathrm{HS} 1$, college, and Pro2 groups had greater than $50 \%$ of players with total arc of motion differences $>5^{\circ}$.

Conclusions: Range of motion alterations exist across ages and levels of competition with $12 \mathrm{u}$ and $14 \mathrm{u}$ players having less internal rotation than the older groups and youth pitchers having less total range of motion than HS1.

\footnotetext{
a Corresponding Author: 


\section{Level of Evidence}

2

\section{INTRODUCTION}

The repetitive nature of throwing can result in altered glenohumeral range of motion patterns including increased external rotation (ER) and decreased internal rotation (IR) compared to the non-dominant arm. ${ }^{1-17}$ Glenohumeral internal rotation deficit (GIRD), defined as decreased IR greater than $20^{\circ}$ in the throwing arm compared to the nonthrowing arm, has been reported to be related to injury in professional baseball pitchers. ${ }^{17,18}$ Factors that have been suggested to contribute to GIRD are humeral retrotorsion, ${ }^{11,19,20}$ posterior capsular tightness, ${ }^{1,5,7}$ and muscular changes. ${ }^{12}$ GIRD has been associated with superior labral tears from anterior to posterior, as well as articular sided rotator cuff tears, biceps, and capsular injuries in players of all ability levels, from little league to professional players. ${ }^{6,21-23}$

In addition to assessing for the presence of GIRD, total arc of motion is also a critical measure that should be considered by clinicians working with baseball players. Total arc of motion is obtained by adding the measures of ER and IR on one shoulder together rather than purely evaluating side-to-side IR loss. Shoulder range of motion may contribute to injury risk in baseball players, however conflicting evidence exists in the literature. Side-to-side total arc of motion differences (TAMD) $>5^{\circ}$ is associated with increased injury risk in professional baseball pitchers. ${ }^{18}$ Decreased IR and total arc of motion has been demonstrated to contribute to upper extremity injury in youth, high school, and professional baseball players. ${ }^{6,21-23}$ However, a recent study of 832 high school baseball pitchers and position players indicated that range of motion deficits did not contribute to injury risk. ${ }^{24}$ The conflicting evidence indicates a need for further research on range of motion patterns between competition levels.

Improved understanding of range of motion alterations across ages and levels of competition may allow the identification of risk factors and development of interventions to decrease the incidence of upper extremity injuries in baseball players. No study to date has evaluated range of motion in cohorts of youth, high school, collegiate, and professional levels of competition as part of the same study. The current study is unique because youth, high school, and professional players are examined based on age and not solely on competition level. Previous researchers have examined a wide range of ages together without taking into consideration potential differences that may be present from a developmental standpoint. Baseball participation may vary between younger and older players within each level of competition. The purpose of this study was to compare shoulder range of motion in baseball players across levels of competition and compare the prevalence of GIRD and TAMD between competition levels in pitchers and position players. It was hypothesized that shoulder range of motion would be different between competition levels. Additionally, collegiate and professional pitchers would have a significantly increased prevalence of GIRD and TAMD com- pared to youth and pitchers would have a greater prevalence of GIRD and TAMD than position players due to making a greater number of maximal effort throws over time.

\section{METHODS}

Baseball players were recruited from local youth leagues, high schools, and colleges. In addition, professional (Minor League) baseball players from a single organization volunteered. Both pitchers and position players were recruited by word of mouth. Exclusion criteria included current pain in the arm, shoulder, elbow or shoulder surgery within the last two years. Individuals were excluded if they had a history of injury within the prior six months that did not require surgery, but did result is an absence from play. The Baptist Hospital-Pensacola institutional review board approved this study. Prior to data collection, all testing procedures were explained to each participant and informed consent was obtained. For participants who were less than 18 years old, parental consent and participant assent were obtained. A power analysis for a one-way ANOVA with seven groups was conducted in G*Power (Version 3.1.7; Dusseldorf, Germany) to determine a sufficient sample size using an alpha of 0.05 , a power of 0.80 , and a large effect size $(f=0.40){ }^{25}$ The estimated total sample size was 98 .

Players completed a questionnaire that included questions regarding height, weight, hand dominance, level of participation, main position, years pitched, percentage of teams' games pitched, and history of elbow or shoulder surgery in the last two years. Passive glenohumeral IR and ER range of motion was measured. Glenohumeral range of motion was assessed with the participants supine on an examination table with the arm positioned at $90^{\circ}$ of shoulder abduction and the elbow flexed to $90^{\circ}$. A bolster was placed under the distal humerus to maintain arm position in the plane of the scapula. The position of the scapula was controlled by palpating the coracoid process and monitoring for movement to determine the end range of glenohumeral motion.7,22,23,26-28 Measurements were recorded with a Baseline ${ }^{\circledR}$ digital inclinometer (Fabrication Enterprises, Inc., White Plains, NY) placed along the ulnar shaft with the hand in a pronated position for IR and the digital inclinometer along the ulnar border with the hand in the neutral position for ER. ${ }^{7,22,23,27}$ For all measurements, the inclinometer was placed proximal to the ulnar styloid. Once the end range of motion was reached, the value was recorded. Measurements were taken prior to the season, during preparticipation physical examinations, and participants were instructed to not throw or pitch 48 hours prior to testing. Participants did not perform any upper extremity stretching or warm-up exercises prior to testing. Youth, high school, and college participants had their measurement assessed in late July and professional pitchers had their measurements taken in March prior to spring training. Range of motion was assessed bilaterally and two measurements were recorded for each rotational motion. ${ }^{29}$ The average was then calculated and used for data analysis. A sin- 
Table 1. Participant Demographics. Mean (SD).

\begin{tabular}{|c|c|c|c|c|c|}
\hline Group & Group Characteristics & Age (years) & Height (cm) & Mass (kg) & \% Pitchers \\
\hline $12 \mathrm{u}(\mathrm{n}=30)$ & $11-12$ years old & $12.0(0.5)$ & $153.7(9.6)$ & $49.2(11.3)$ & 63 \\
\hline $14 \mathrm{u}(\mathrm{n}=30)$ & $13-14$ years old & $13.0(0.5)$ & $170.8(8.9)$ & $58.5(12.2)$ & 77 \\
\hline HS1 $(\mathrm{n}=42)$ & $15-16$ years old & $15.0(0.7)$ & $176.2(8.4)$ & $69.5(11.9)$ & 52 \\
\hline HS2 $(\mathrm{n}=25)$ & $17-18$ years old & $17.0(0.7)$ & $183.2(5.6)$ & $79.6(9.1)$ & 60 \\
\hline College $(\mathrm{n}=22)$ & College players & $19.1(0.9)$ & $177.5(26.1)$ & $81.0(18.2)$ & 41 \\
\hline Pro 1 $(\mathrm{n}=37)$ & $17-22$ years old professional players & $20.4(1.3)$ & $185.3(5.4)$ & $91.0(8.7)$ & 32 \\
\hline Pro 2 $(\mathrm{n}=37)$ & 23 years and older professional players & $24.9(2.5)$ & $186.2(6.0)$ & $94.6(8.3)$ & 30 \\
\hline
\end{tabular}

gle, board-certified orthopaedic surgeon performed range of motion measurements to reduce measurement variability. A single examiner positioned the arm for all measurements to reduce measurement variability. Test-retest reliability was performed on seven individuals, prior to initiating the study, to determine intrarater reliability. The examiner reported excellent intrarater reliability for all range of motion measures, with intraclass correlation coefficient (ICC) and minimal detectable change $(\mathrm{MDC})$ : $\operatorname{IR}-\operatorname{ICC}(3,2)=0.94$ $\operatorname{MDC90}=6.8^{\circ} ; \operatorname{ER}-\operatorname{ICC}(3,2)=0.91, \operatorname{MDC} 90=7.8^{\circ} ;$ $\operatorname{GIRD}-\operatorname{ICC}(3,2)=0.95, \operatorname{MDC} 90=5.2^{\circ} ; \mathrm{TAMD}-\operatorname{ICC}(3,2)=$ $0.996, \operatorname{MDC} 90=5.5^{\circ}$.

Participants were divided into seven groups for analysis. The following groups were assigned: $12 \mathrm{u}$ (11-12 years; $n=30), 14 u$ (13-14 years; $n=30$ ), High School 1 (HS 1; 15-16 year; $n=42$ ), High School 2 (HS 2; 17-18 years; $n=25$ ), College $(n=22)$, Professional 1 (Pro1; 17-22 years; $n=37)$ and Professional 2 (Pro2; 23 and older; $n=37$ ). Data were analyzed using Statistical Package for the Social Sciences software (version 22; SPSS Inc., Chicago, IL, USA).

Means and standard deviations were calculated for each group's IR and ER range of motion for both the dominant (throwing) and non-dominant arms. Differences in IR and ER values between arms were calculated, and the percentage of participants in each group with GIRD in the dominant arm $>20^{\circ}$ was calculated. Total arc of motion was calculated by the sum of IR and ER. ${ }^{13}$ The percentage of participants in each group with TAMD $>5^{\circ}$ and GIRD was also calculated. Multiple one-way analyses of variance (ANOVA) were performed to determine differences between groups. Tukey test for post-hoc analysis on significant findings was employed to determine which competition levels of baseball players were significantly different. A one-way ANOVA was also performed to determine if range of motion in pitchers was significantly different between competition levels. Chi-square tests were performed to examine the differences in prevalence of GIRD and TAMD between pitchers and position players. The significance level was $p \leqslant 0.05$ for all analyses.

\section{RESULTS}

Participant demographics and characteristics across the seven groups (12u, 14u, HS1, HS2, College, Pro1, and Pro2) are presented in Table 1 . Significant differences were ob-

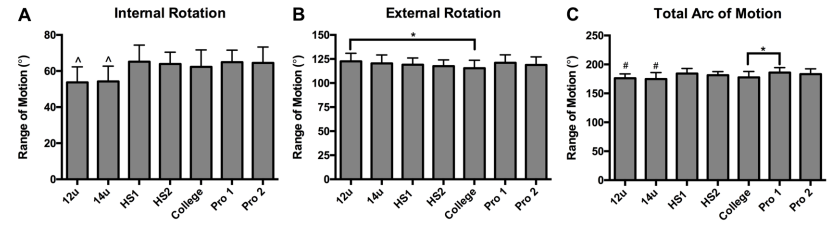

Figure 1. Internal rotation (A), external rotation (B), and total arc of motion (C) of the dominant arm between groups. ^Significantly less than all other groups. "Significant difference between groups. ${ }^{\#}$ Significantly less than the HS1, Pro 1, and Pro 2 groups.

served in height and mass across the seven groups. Data describing dominant arm range of motion in baseball players are presented in Figure 1. Significant differences were observed in IR $(p<0.0001)$, ER $(p=0.038)$, and total arc of motion $(p<0.0001)$ measures between groups of baseball players. $12 \mathrm{u}$ and $14 \mathrm{u}$ players had significantly lower IR compared to the high school, collegiate and professional players. ER was significantly greater in $12 \mathrm{u}$ players compared to college players (mean difference $=7.1^{\circ}$ ). Total arc of motion was significantly less in $12 \mathrm{u}$ and $14 \mathrm{u}$ players compared to HS1 and Pro1 \& Pro2 players. College baseball players had significantly less total arc of motion than Pro1 players. When examining side-to-side differences across groups (Table 2), significance was not reached for any measurement. $14 \mathrm{u}$ players had the highest prevalence of GIRD at $30.3 \%$ and $73.3 \%$ of $12 \mathrm{u}$ players had TAMD $>5^{\circ}$.

Significant differences were observed in dominant arm range of motion of pitchers (Figure 2). IR was significantly less in $12 \mathrm{u}$ and $14 \mathrm{u}$ pitchers compared to HS1 and Pro1 pitchers $(p<0.0001) .12 \mathrm{u}$ pitchers also had less IR than college pitchers (mean difference $=10.3^{\circ} ; p<0.0001$ ). Total arc of motion was also significantly less for $12 \mathrm{u}$ and $14 \mathrm{u}$ pitchers compared to HS1 pitchers (mean difference (12u vs HS1) $=11.1^{\circ}$; mean difference $(14 \mathrm{u}$ vs HS1 $\left.)=11.8^{\circ} ; p=0.0004\right)$. No significant differences were found in side-to-side range of motion in pitchers (Table 3 ). The $14 \mathrm{u}$ group of pitchers had the highest prevalence of GIRD $>20^{\circ}(27.8 \%)$. More than $70 \%$ of $12 \mathrm{u}$ and Pro 2 pitchers had TAMD $>5^{\circ}$. Across all competition levels, $14.4 \%$ of position players had GIRD and $50 \%$ had TAMD $>5^{\circ}$. For pitchers across all competition levels, $21 \%$ had GIRD and $58.1 \%$ had TAMD $>5^{\circ}$. There was no 
Table 2. Side-to-Side Difference in Range of Motion ( ${ }^{\circ}$ ) between Groups. Mean (SD).

\begin{tabular}{|c|c|c|c|c|c|}
\hline Group & $\begin{array}{c}\text { Glenohumeral Internal } \\
\text { Rotation Difference }\end{array}$ & $\begin{array}{c}\text { External } \\
\text { Rotation } \\
\text { Difference }\end{array}$ & $\begin{array}{c}\text { Total Arc of } \\
\text { Motion } \\
\text { Difference }\end{array}$ & $\begin{array}{c}\text { GIRD } \\
\text { (\%) }\end{array}$ & $\begin{array}{c}\text { Total Arc of Motion } \\
\text { Difference }>5^{\circ}(\%)\end{array}$ \\
\hline $12 u$ & $-13.1(9.8)$ & $6.7(8.3)$ & $-6.4(11.6)$ & 20 & 73 \\
\hline $14 u$ & $-15.7(10.2)$ & $10.2(9.7)$ & $-5.5(11.5)$ & 30 & 53 \\
\hline HS1 & $-9.3(7.8)$ & $7.3(7.1)$ & $-2.0(8.1)$ & 17 & 52 \\
\hline HS2 & $-11.4(7.5)$ & $6.2(6.1)$ & $-5.2(6.9)$ & 16 & 40 \\
\hline College & $-12.0(8.6)$ & $7.3(7.4)$ & $-4.7(9.3)$ & 18 & 50 \\
\hline Pro 1 & $-10.0(7.4)$ & $6.3(7.2)$ & $-3.7(8.7)$ & 14 & 43 \\
\hline Pro 2 & $-12.2(9.5)$ & $8.4(10.2)$ & $-3.8(9.0)$ & 24 & 60 \\
\hline
\end{tabular}

Table 3. Side-to-Side Differences in Range of Motion $\left({ }^{\circ}\right)$ in Pitchers. Mean (SD).

\begin{tabular}{|c|c|c|c|c|c|}
\hline Group & $\begin{array}{c}\text { Glenohumeral Internal } \\
\text { Rotation Difference }\end{array}$ & $\begin{array}{c}\text { External } \\
\text { Rotation } \\
\text { Difference }\end{array}$ & $\begin{array}{c}\text { Total Arc of } \\
\text { Motion } \\
\text { Difference }\end{array}$ & $\begin{array}{c}\text { GIRD } \\
\text { (\%) }\end{array}$ & $\begin{array}{c}\text { Total Arc of Motion } \\
\text { Difference }>5^{\circ} \text { (\%) }\end{array}$ \\
\hline $\begin{array}{c}12 u \\
(n=20)\end{array}$ & $-14.2(11.2)$ & $7.7(9.5)$ & $-6.6(12.6)$ & 20 & 70 \\
\hline $\begin{array}{c}14 u \\
(n=18)\end{array}$ & $-13.6(10.1)$ & $10.8(9.1)$ & $-2.8(9.93)$ & 28 & 56 \\
\hline $\begin{array}{c}\text { HS 1 } \\
(n=22)\end{array}$ & $-9.3(7.7)$ & $8.2(8.2)$ & $-1.1(8.2)$ & 10 & 55 \\
\hline $\begin{array}{c}\text { HS 2 } \\
(n=14)\end{array}$ & $-11.9(6.4)$ & $7.3(6.3)$ & $-4.6(6.7)$ & 21 & 43 \\
\hline $\begin{array}{c}\text { Col } \\
(n=9)\end{array}$ & $-15.7(6.5)$ & $12.7(4.2)$ & $-3.0(7.3)$ & 22 & 44 \\
\hline $\begin{array}{c}\text { Pro 1 } \\
(n=12)\end{array}$ & $-11.9(7.2)$ & $5.8(7.4)$ & $-6.2(8.6)$ & 8 & 25 \\
\hline $\begin{array}{c}\text { Pro 2 } \\
(n=11)\end{array}$ & $-17.9(9.6)$ & $12.8(9.8)$ & $-5.1(7.9)$ & 27 & 73 \\
\hline
\end{tabular}

difference in the prevalence of GIRD between pitchers and position players $(\chi=1.7 ; p=0.199)$. There was also no difference in the prevalence of TAMD $>5^{\circ}$ between pitchers and position players $(\chi=1.5 ; p=0.226)$.

\section{DISCUSSION}

The most important finding of this study is that range of motion had little variation among the competition levels of baseball players and in the pitcher subgroup. The hypothesis that collegiate and professional players and pitchers would have a higher prevalence of GIRD and TAMD compared to youth was not supported however a few significant differences were observed between groups. Youth players $(12 \mathrm{u}$ and $14 \mathrm{u})$ had significantly less IR and total arc of motion than players in higher competition levels. IR and total arc of motion were also significantly less in youth $(12 u$ and $14 \mathrm{u}$ ) pitchers compared to high school (HS1), college, and professional (Pro1) pitchers. The secondary hypothesis was also not supported because the prevalence of GIRD and TAMD $>5^{\circ}$ was similar between pitchers and position play-

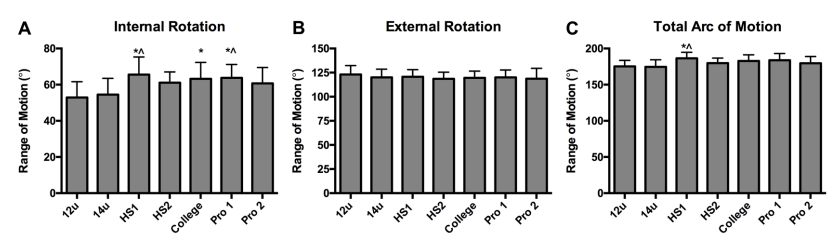

Figure 2. Internal rotation(A), external rotation (B), and total arc of motion (C) of the dominant arm in pitchers. *Significantly greater than $12 u$.

^Significantly greater than $14 u$.

ers.

Decreased IR and ER range of motion with age in little league and adolescent baseball players ages 8-16 has been reported. ${ }^{10}$ In 10-12 year old pitchers, GIRD was present in 10 of the 25 players and there was no significant difference in ER compared to the non-dominant arm suggesting the loss of IR can occur prior to gains in ER. ${ }^{9}$ In contrast, the current results show greater IR from high school age and throughout the higher levels of competition, compared to 
$12 u$ and $14 u$. Repetitive eccentric contractions of the posterior musculature during throwing can lead to tightness and posteroinferior capsular contracture may contributed to loss of IR. ${ }^{1}$ It is possible that the difference in IR was due to the relatively small sample size of participants in each age group. The increased IR in higher competition levels may also be related to an increased awareness of the importance of maintaining range of motion. Furthermore, from high school through the professional competition levels, players have access to medical and strength and conditioning personnel that can educate and stretching programs for players. Youth baseball players often do not have access to these resources.

Maintaining total arc of motion in the presence of GIRD may be more important than solely focusing on GIRD because gains in ER may compensate for loss of IR. ${ }^{30}$ Increased ER in the throwing shoulder compared to the nonthrowing shoulder is an adaptation that has been reported in baseball players. ${ }^{19}$ Humeral retrotorsion is thought to be a contributing factor to increased ER and is an adaptation that may be due to participation in overhead sports before skeletal maturity occurs. ${ }^{31-33}$ Increased retrotorsion of the humerus along with increased external rotation in the dominant arms of the pitchers has previously been reported. ${ }^{19}$ ER range of motion was significantly greater in the $12 \mathrm{u}$ group compared to the college group, which was unexpected due to the physical changes that occur through maturation. It is assumed that the $12 \mathrm{u}$ group of players had not reached skeletal maturity and likely had not gain the benefit of the osseous adaptations that occur with throwing. TAMD $>5^{\circ}$ has been associated with increased injury risk in professional baseball pitchers ${ }^{18}$ but it is unclear if this cut-off value differentiates risk of injury in players in lower competition levels. The $12 \mathrm{u}, 14 \mathrm{u}$, HS1, college, and
Pro2 groups had greater than $50 \%$ of players with TAMD $>5^{\circ}$. The $12 \mathrm{u}$ group had the highest percentage of players with TAMD (73\%). Despite TAMD $>5^{\circ}$ frequently referenced in the literature this value may be within measurement error and have limited clinical significance.

Limitations of the study include that this was a crosssectional study conducted at a single point in time comparing different competition levels of baseball players. Tanner staging was not performed to determine physical maturity of the players thus there could have been some overlap between players in the younger groups that may have affected the results. Another limitation to this study is the small sample of pitchers that were compared across competition levels. Youth baseball players frequently play multiple positions until higher levels of competition are reached and they transition to a single position. Future research should aim to longitudinally assess changes in range of motion and humeral retrotorsion in young baseball players over the course of their playing careers. This future research would allow for clinicians to gain a better understanding of the physiological adaptations that contributed to altered range of motion patterns in baseball players.

\section{CONCLUSION}

The results of this study indicate that range of motion was similar across competition levels of baseball players and the pitcher subgroup. More than $70 \%$ of the $12 \mathrm{u}$ and Pro 2 groups had TAMD $>5^{\circ}$. These results indicate that clinicians should monitor range of motion in all age groups of baseball players and pitchers.

Submitted: June 07, 2021 CST, Accepted: September 28, 2021 CST 


\section{REFERENCES}

1. Burkhart SS, Morgan CD, Kibler WB. The disabled throwing shoulder: spectrum of pathology Part I: pathoanatomy and biomechanics. Arthroscopy. 2003;19(4):404-420. doi:10.1053/jars.2003.50128

2. Chandler TJ, Kibler WB, Uhl TL, Wooten B, Kiser A, Stone E. Flexibility comparisons of junior elite tennis players to other athletes. Am J Sports Med. 1990;18(2):134-136. doi:10.1177/03635465900180020 $\underline{4}$

3. Dwelly PM, Tripp BL, Tripp PA, Eberman LE, Gorin $S$. Glenohumeral rotational range of motion in collegiate overhead-throwing athletes during an athletic season. J Athl Train. 2009;44(6):611-616. do $\mathrm{i}: 10.4085 / 1062-6050-44.6 .611$

4. Kibler WB, Sciascia A, Thomas SJ. Glenohumeral internal rotation deficit: pathogenesis and response to acute throwing. Sports Med Arthrosc Rev. 2012;20(1):34-38. doi:10.1097/isa.0b013e318244853e

5. Tyler TF, Nicholas SJ, Lee SJ, Mullaney M, McHugh MP. Correction of posterior shoulder tightness is associated with symptom resolution in patients with internal impingement. Am J Sports Med. 2010;38(1):114-119. doi:10.1177/0363546509346050

6. Lintner D, Mayol M, Uzodinma O, Jones R, Labossiere D. Glenohumeral internal rotation deficits in professional pitchers enrolled in an internal rotation stretching program. Am J Sports Med. 2007;35(4):617-621. doi:10.1177/0363546506296736

7. Shanley E, Thigpen CA, Clark JC, et al. Changes in passive range of motion and development of glenohumeral internal rotation deficit (GIRD) in the professional pitching shoulder between spring training in two consecutive years. J Shoulder Elbow Surg. 2012;21(11):1605-1612. doi:10.1016/j.jse.2011.1 1.035

8. Thomas SJ, Swanik KA, Swanik CB, Kelly JD. Internal rotation and scapular position differences: a comparison of collegiate and high school baseball players. J Athl Train. 2010;45(1):44-50. doi:10.4085/10 62-6050-45.1.44

9. Nakamizo H, Nakamura Y, Nobuhara K, Yamamoto $\mathrm{T}$. Loss of glenohumeral internal rotation in little league pitchers: a biomechanical study. J Shoulder Elbow Surg. 2008;17(5):795-801. doi:10.1016/j.jse.200 $\underline{8.02 .013}$
10. Meister K, Day T, Horodyski M, Kaminski TW, Wasik MP, Tillman S. Rotational motion changes in the glenohumeral joint of the adolescent/Little League baseball player. Am J Sports Med. 2005;33(5):693-698. doi:10.1177/0363546504269936

11. Reagan KM, Meister K, Horodyski MB, Werner DW, Carruthers C, Wilk K. Humeral retroversion and its relationship to glenohumeral rotation in the shoulder of college baseball players. Am J Sports Med. 2002;30(3):354-360. doi:10.1177/03635465020300030 901

12. Reinold MM, Wilk KE, Macrina LC, et al. Changes in shoulder and elbow passive range of motion after pitching in professional baseball players. Am J Sports Med. 2008;36(3):523-527. doi:10.1177/0363546507308 $\underline{935}$

13. Wilk KE, Meister K, Andrews JR. Current concepts in the rehabilitation of the overhead throwing athlete. Am J Sports Med. 2002;30(1):136-151. doi:1 $\underline{0.1177 / 03635465020300011201}$

14. Hibberd EE, Oyama S, Myers JB. Increase in humeral retrotorsion accounts for age-related increase in glenohumeral internal rotation deficit in youth and adolescent baseball players. Am J Sports Med. 2014;42(4):851-858. doi:10.1177/036354651351 $\underline{9325}$

15. Hibberd EE, Oyama S, Tatman J, Myers JB. Dominant-limb range-of-motion and humeralretrotorsion adaptation in collegiate baseball and softball position players. $J$ Athl Train. 2014;49(4):507-513. doi:10.4085/1062-6050-49.3.23

16. Oyama S, Hibberd EE, Myers JB. Changes in humeral torsion and shoulder rotation range of motion in high school baseball players over a 1-year period. Clin Biomech (Bristol, Avon). 2013;28(3):268-272. doi:10.1016/j.clinbiomech.201 3.01 .014

17. Wilk KE, Macrina LC, Fleisig GS, et al. Correlation of glenohumeral internal rotation deficit and total rotational motion to shoulder injuries in professional baseball pitchers. Am J Sports Med. 2011;39(2):329-335. doi:10.1177/0363546510384223

18. Wilk KE, Macrina LC, Fleisig GS, et al. Deficits in glenohumeral passive range of motion increase risk of elbow injury in professional baseball pitchers: A prospective study. Am J Sports Med. 2014;42(9):2075-2081. doi:10.1177/036354651453839 
19. Crockett HC, Gross LB, Wilk KE, et al. Osseous adaptation and range of motion at the glenohumeral joint in professional baseball pitchers. Am J Sports Med. 2002;30(1):20-26. doi:10.1177/03635465020300 $\underline{011701}$

20. Wyland DJ, Pill SG, Shanley E, et al. Bony adaptation of the proximal humerus and glenoid correlate within the throwing shoulder of professional baseball pitchers. Am J Sports Med. 2012;40(8):1858-1862. doi:10.1177/036354651245272 $\underline{0}$

21. Braun S, Kokmeyer D, Millett PJ. Shoulder injuries in the throwing athlete. J Bone Joint Surg Am. 2009;91(4):966-978. doi:10.2106/jbjs.h.01341

22. Shanley E, Kissenberth MJ, Thigpen CA, et al. Preseason shoulder range of motion screening as a predictor of injury among youth and adolescent baseball pitchers. J Shoulder Elbow Surg. 2015;24(7):1005-1013. doi:10.1016/j.jse.2015.03.012

23. Shanley E, Rauh MJ, Michener LA, Ellenbecker TS, Garrison JC, Thigpen CA. Shoulder range of motion measures as risk factors for shoulder and elbow injuries in high school softball and baseball players. Am J Sports Med. 2011;39(9):1997-2006. doi:10.1177/0 363546511408876

24. Oyama S, Hibberd EE, Myers JB. Preseason screening of shoulder range of motion and humeral retrotorsion does not predict injury in high school baseball players. J Shoulder Elbow Surg.

2017;26(7):1182-1189. doi:10.1016/j.jse.2017.03.038

25. Faul F, Erdfelder E, Buchner A, Lang A-G. G*Power Version 3.1.7 [computer software].; 2013. http://www.p sycho.uni-duesseldorf.de/abteilungen/aap/gpower3/d ownload-and-register. Accessed February 23, 2018.
26. Shanley E, Michener LA, Ellenbecker TS, Raugh MJ. Shoulder range of motion, pitch count, and injuries among interscholastic female softball pitchers: A descriptive study. Int J Sports Phys Ther. 2012;7(5):548-556.

27. Garrison JC, Cole MA, Conway JE, Macko MJ, Thigpen C, Shanley E. Shoulder range of motion deficits in baseball players with an ulnar collateral ligament tear. Am J Sports Med. 2012;40(11):2597-2603. doi:10.1177/03635465124591 $\underline{75}$

28. Wilk KE, Reinold MM, Macrina LC, et al. Glenohumeral internal rotation measurements differ depending on stabilization techniques. Sports Health. 2009;1(2):131-136. doi:10.1177/1941738108331201

29. Rosen M, Meijer K, Tucker S, et al. Shoulder range of motion deficits in youth throwers presenting with elbow pain. Sports Health. 2021:194173812110363. do i:10.1177/19417381211036387

30. Manske R, Wilk KE, Davies G, Ellenbecker T, Reinold M. Glenohumeral motion deficits: Friend or foe? Int J Sports Phys Ther. 2013;8(5):537-553.

31. Osbahr DC, Cannon DL, Speer KP. Retrotorsion of the humerus in the throwing shoulder of college baseball pitchers. Am J Sports Med. 2002;30(3):347-353. doi:10.1177/03635465020300030 $\underline{801}$

32. Pieper HG. Humeral torsion in the throwing arm of handball players. Am J Sports Med. 1998;26(2):247-253. doi:10.1177/03635465980260021 501

33. Crockett HC, Gross LB, Wilk KE, et al. Osseous adaptation and range of motion at the glenohumeral joint in professional baseball pitchers. Am J Sports Med. 2002;30(1):20-28. doi:10.1177/03635465020300 $\underline{011701}$ 